\title{
A CONFORMAÇÃO DA INDÚSTRIA BRASILEIRA: CENÁRIOS INTERNACIONAL E NACIONAL
}

\author{
Wallace Marcelino Pereira* \\ Silvio Antonio Ferraz Cario ${ }^{\dagger}$
}

Resumo: O objetivo deste artigo é investigar a posição relativa brasileira em relação ao resto do mundo, e evidenciar a existência de perda de capacidade da indústria nacional de levar a cabo um processo de desenvolvimento econômico capaz colocar o Brasil, dentre aqueles países, cuja renda per capita e incorporação de progresso técnico são os motores da transformação econômica e social. Os resultados evidenciaram que o deslocamento brasileiro para faixas inexpressivas no quadro de países exportadores de manufaturados, é reflexo da mudança da dinâmica internacional de capitais que se tornaram mais financeirizadas, da perda de capacidade da indústria nacional em acompanhar a corrida tecnológica internacional, bem como apresenta relação com o grau de abertura da economia brasileira, após meados da década de 90. A atualidade tem mostrado que se até 2005 podia-se constatar que "o passado havia cobrado do presente os 25 anos em que a estratégia de desenvolvimento delegou ao capital estrangeiro o papel de agente transformador e financiador do crescimento, os dados analisados sugerem que o passado não só continua cobrando as falhas de estratégia, como o presente tem paulatinamente restringido o tamanho das janelas de acesso ao novo paradigma técnico produtivo do futuro.

\section{Palavras chave: Desindustrialização - Mudança Estrutural - Indústria - Comércio Internacional - Estratégia de Desenvolvimento.}

Abstract: The purpose of this article is to investigate the Brazilian position relative to the rest of the world, and demonstrate the existence of the domestic industry capacity loss carry out a capable economic development process put Brazil among those countries whose income per capita and incorporation of technical progress are the engines of economic and social transformation. The results showed that the Brazilian moving to inexpressive bands in the context of countries exporting manufactured goods, reflects the changing international dynamics of capital that have become more financeirizadas, the loss of the domestic industry capacity to monitor the international technology race and presents relationship with the degree of openness of the Brazilian economy after the mid-90's today has shown that by 2005 could be seen that "the past had charged the present 25 years in the development strategy has delegated to foreign capital the role of change agent and financier of growth, the data suggest that the past continues not only charging the strategy of failure, as this has gradually restricted the size of the windows of access to new production technician future paradigm.

Keywords: Deindustrialization - Structural Change - Manufacture - International Trade -
Development Strategy

\section{Área 2: Comércio Internacional e Cadeias de Valor}

JEL: R1

\footnotetext{
*Doutorando em Economia pelo CEDEPLAR/UFMG. Contato: wallacemp2000@yahoo.com.br

${ }^{\dagger}$ Professor Doutor em Economia do DERI e PPGECO/ UFSC. Contato: fecario@yahoo.com.br
} 


\section{Introdução}

A partir de meados da década de 80 a economia brasileira vem apresentando queda sistemática da participação da indústria na formação de seu Produto Interno Bruto (PIB), o que tem chamado a atenção de diversos pesquisadores para a existência de um processo denominado desindustrialização relativa (COMIN, 2009; SILVA, 2012). Tal comportamento do setor industrial brasileiro tem suscitado um debate intenso na medida em a indústria de transformação é considerada como o motor do crescimento com reflexo sobre o desenvolvimento econômico dos países.

O presente artigo aborda o problema da desindustrialização em dois planos, a saber: a desindustrialização em nível mundial e brasileira em relação ao resto do mundo, e a desindustrialização brasileira em si. O objetivo é investigar a posição relativa brasileira em relação ao resto do mundo, e evidenciar a existência de perda de capacidade da indústria nacional de levar a cabo um processo de desenvolvimento econômico capaz colocar o Brasil, dentre aqueles países, cuja renda per capita e incorporação de progresso técnico são os motores da transformação econômica e social.

\section{Aspectos teóricos sobre a desindustrialização}

Por volta da década de 70 os países desenvolvidos começaram a apresentar uma queda sistemática da participação da indústria na composição do PIB. Entretanto, somente a partir da divulgação do relatório da United Nations Conference on Trade and Development (UNCTAD, 2003) deu-se início a um intenso debate buscando não só conceituar o fenômeno, mas também entender a origem e as causas do processo de desindustrialização em curso nos países desenvolvidos.

Neste sentido, quando, inicialmente, se levanta a literatura internacional sobre desindustrialização, esta aponta três eixos básicos de análise, a saber: 1) queda do emprego (em termos absolutos e/ou em relação ao emprego total da nação); 2) queda da produção (em termos absolutos e/ou em relação ao PIB do país); e 3) deterioração do balanço de pagamentos, em especial, a deterioração do saldo comercial da indústria de transformação (MORCEIRO, 2012).

Em Palma (2005) a desindustrialização é entendida e definida em duas fases, sendo elas, a primeira marcada pela queda em termos relativos do emprego industrial, e posteriormente em termos absolutos ao passo que o setor de serviços continua a ser a fonte principal de absorção de mão de obra. Buscando uma definição mais abrangente Tregenna (2009) coloca que a desindustrialização é um fenômeno em que não só o emprego industrial, mas também o valor adicionado da indústria se reduzem em relação ao emprego total e do PIB, respectivamente.

A abordagem do balanço de pagamentos ou do comércio internacional não considera o emprego nem a produção como relevantes. Autores como Singh, (1977); Cairncross, (1978); Blackaby, (1978) consideram que uma diminuição da participação do emprego manufatureiro na economia total pode ser desejada se vier acompanhada de aumentos na produtividade. Para estes autores a queda do emprego industrial só se torna preocupante caso tal comportamento ponha em risco a capacidade do país em pagar suas importações, ampliando deste modo à restrição ao crescimento econômico.

Em linha com Tregenna (2009), Oreiro e Feijó (2010, pag. 221) afirmam que “uma economia não se desindustrializa quando a produção industrial está estagnada ou em queda, mas quando o setor industrial perde importância como fonte geradora de empregos e/ ou de valor adicionado para uma determinada economia” (OREIRO e FEIJO, 2010, pg 221). Neste contexto, inserem-se a perda de importância de segmentos industriais relevantes e ruptura de elos em cadeias produtivas sem necessariamente o valor total da produção se alterar.

No caso brasileiro, autores apontam a ocorrência de um processo de desindustrialização relativa, através de perda de participação da indústria na criação da riqueza nacional do que absoluta, expressa em fechamento de unidades produtivas ou redução do valor real da produção (COMIN, 2009; SILVA, 2012). Este processo inicia-se na década de 80 quando a crise econômica decorrente da exaustão do padrão de financiamento externo e fragilidade fiscal do Estado contribuíram para atenuar a contribuição da indústria 
na formação da riqueza nacional, em momento de mudança do paradigma tecno-produtivo mundial. A crise da dívida externa levou a formulação de uma política econômica centrada na busca de superávits comerciais significativos para enfrentar a retração das fontes externas de financiamento, e estabelecendo a necessidade de contenção de importações e o incentivo às exportações (LAPLANE e SARTI, 2006).

A abertura econômica dos anos 90 somada aos processos de desregulamentação e privatização constituíram o norte da direção de política econômica. Como resultado dessa nova fase de política econômica, centrada na concorrência como motor do crescimento, foi observada a contínua perda, por parte das empresas públicas, da capacidade de financiamento, bem como o arrefecimento da capacitação tecnológica do setor privado que se enfraqueceu pela ausência de demanda e pela redução do ritmo de imposição, em termos de normas e padrões técnicos e de qualidade para aquisição de equipamentos e serviços (FERRAZ et all, 1995).

Em termos de configuração industrial, o Brasil adentra os anos 2000 com trajetória marcada pela tendência de impossibilidade em incorporar a nova onda tecnológica, marcada pelo uso de material eletrônico e de comunicação, ao passo que as indústrias baseadas em recursos minerais passaram a ganhar cada vez mais espaço. (CARNEIRO, 2008). A especialização em atividades intensivas em recursos naturais somada ao abandono da busca por inovações e menor exposição à concorrência externa levaram o país a um processo chamado de "especialização regressiva” da produção industrial (LAPLANE e SARTI, 2006).

Aliado a este problema Bresser e Marconi (2008) colocam que a partir dos anos 90, o Brasil ao optar por dar início ao processo de abertura comercial e financeira, permitiu a eliminação dos mecanismos - política de controles tarifários, alfandegários e cambiais - capazes de neutralizar a “doença holandesa” que vinham sendo utilizados no passado. Como o Brasil possui vantagens comparativas na produção de diversas commodities, a "doença holandesa” começou a se manifestar de modo lento e gradativo, o que ocorre em países que se encontram em estágios de evolução industrial mais significativo. Em a "Maldição dos recursos naturais" Bresser Pereira (2005) explica que a apreciação artificial do câmbio advinha da condição estrutural da economia brasileira ligada à maldição dos recursos naturais, se por um lado permitiu a entrada significativa de divisas internacionais, por outro provocou consequências nefastas para a estrutura industrial, a desindustrialização.

Feijó e Oliveira (2013) também apontam que as dificuldades na indústria brasileira têm suas raízes no processo de desenvolvimento dos últimos vinte anos marcada pela direção no sentido de diminuir o peso relativo de setores intensivos em tecnologia. Ainda conforme os autores, em decorrência disso podese duas consequências, a saber: 1) em função de uma manufatura menos densa em termos de elos da cadeia produtivas faz com que parte dos estímulos de demanda agregada sejam transferidos para o exterior, dado que a oferta é atendida por bens e serviços importados; 2) Enfraquecimento das ligações dos setores industriais com demais setores da economia.

Em complemento, soma-se o tratamento analítico de Arend (2014) que analisando o lugar do Brasil no processo de transformação industrial mundial aponta que a estrutura industrial brasileira vem apresentando relativa rigidez e heterogeneidade com tendência ao aprofundamento de sua especialização produtiva em detrimento de setores mais dinâmicos. O Brasil vem apresentando reduzido dinamismo industrial não apenas na conjuntura atual, mas desde a década de 1980 em relação ao mundo, à América Latina, às economias desenvolvidas e às economias em desenvolvimento, e também em relação à África e à Oceania em desenvolvimento, cujo respectivo período coincide, do ponto de vista interno com o fim de políticas industriais, liberalização comercial e financeira e sobrevalorização cambial. E externamente, com a nova revolução tecnológica e industrial, a configuração de uma nova geografia industrial, comandada por forte atuação estatal em determinados países, e por novas formas globais de produção e comercialização de mercadorias (AREND, 2014).

O processo de desindustrialização da economia brasileira na visão ortodoxa deve-se, em última estância, a ajuste de mercado. Para Bonelli, Pessôa e Matos (2013) o processo de desindustrialização brasileira é natural, e se enquadra no movimento global dos países desenvolvidos no sentido de convergir para o nível ideal. Avaliando 170 países em um período de 40 anos, os referidos autores constatam que o 
Brasil sofre de "doença soviética”, entendida como uma indústria muito acima do padrão internacional quando se considera o grau de desenvolvimento, população, tecnologia, dotação de recursos naturais. A indústria brasileira participava no PIB em um nível muito acima do nível previsto para os padrões do Brasil enquanto país em desenvolvimento.

\section{A indústria no mundo - caminho da desindustrialização}

As taxas de crescimento do Produto Nacional nos últimos 45 anos, Gráfico 01, têm mostrado que a última década vem apresentando um ritmo de crescimento na geração de riqueza, menor que em períodos anteriores. Excetuando a China e a Índia que têm apresentado taxas de crescimento de seu produto mais consistentes ao longo de décadas, os demais países têm tido incrementos relativamente menores ao longo do tempo.

Mais precisamente a Europa e os Estado Unidos, que alcançaram a maturidade de seus parques produtivos exibiram taxas de crescimento menores em relação aos países em desenvolvimento, e principalmente, aos países asiáticos. As Américas do Sul e Central, ao longo das últimas quatro décadas, têm mostrado sua "vocação" às oscilações na taxa de crescimento de seu produto, evidentemente influenciado pela dinâmica de seus principais países como o Brasil, a Argentina, o México e o Chile, e em função da forma como se inserem na economia internacional.

Gráfico 1: Taxa de crescimento médio anual do Produto Nacional de países selecionados, 1970 2014 (\%).

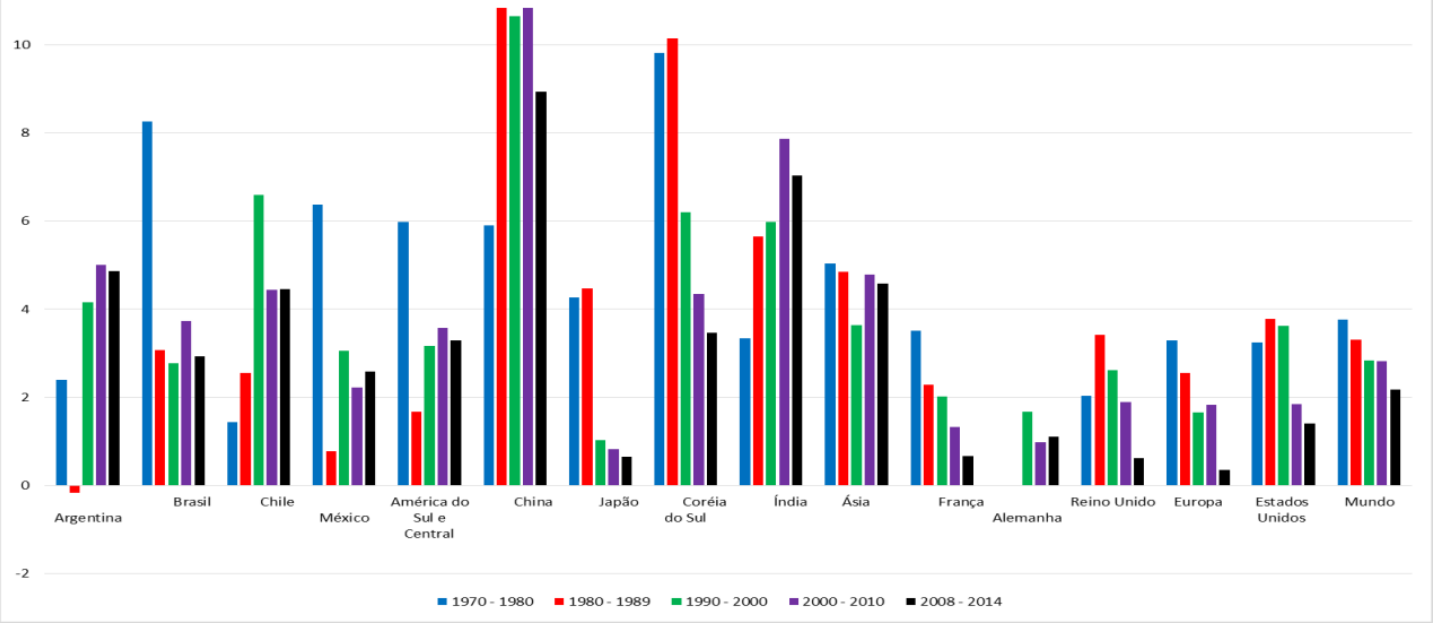

Fonte: Elaboração a partir dos dados da UNCTADSTAT.

Como aponta o Gráfico 01 a década de 70 foi o período áureo do crescimento econômico brasileiro, e também marcado por forte intervenção estatal por meio dos Planos Nacionais de Desenvolvimento que levaram a economia brasileira crescer anualmente em média valores próximos de 10\%. Esta década, cujo fenômeno econômico mais importante foi o Milagre Econômico, viu a indústria de transformação atingir valores elevados de participação no PIB, sugerindo que o Brasil finalmente encontrara o caminho do progresso. Entrementes, as décadas de 80 e 90 evidenciaram ser outro o caminho brasileiro, marcado por baixas taxas de crescimento econômico se comparado ao período anterior, em média 3\% ao ano, e a reversão da trajetória industrial brasileira que passa a ter comportamento muito similar ao dos países desenvolvidos. O comportamento da economia brasileira, a 
partir da década de 80 destoa de economias como a do Chile e da Argentina, mas por ser a economia mais industrializada da América Latina contribui decisivamente no ritmo de crescimento da região.

O processo de desindustrialização vem ocorrendo no mundo desenvolvido desde a década de 70. Estudos realizados por Rowthorn e Ramaswany (1999); Rowthorn e Ramaswany (1999); Rowthorn e Ramaswany (1997); Palma (2005) e Tregenna (2009) identificaram, e apontaram esse processo como resultado do aumento da produtividade da indústria, cujo consequência foi a perda de participação desta no PIB, e no emprego total dos países avançados. Em decorrência desse processo a indústria de transformação no mundo, conforme o Gráfico 02, seguiu essa tendência, desvelando um declínio contínuo até a década de 2000, tanto a preços correntes, quanto a preços constantes, quando a partir de então estabilizou-se, ambas, por volta de $16 \%$. Em decorrência deste fenômeno global, todos os países, principalmente aqueles em desenvolvimento, tem sofrido em grau e extensão diferenciada da queda de participação mundial da indústria na geração de riqueza, muito embora por traz desse processo, haja um deslocamento do capital e de suas fontes de geração de valor, rumo aos países do leste asiático.

\section{Gráfico 2: Evolução da participação da Indústria de Transformação do mundo em relação ao PIB} mundial, 1970 - 2013 (\%).

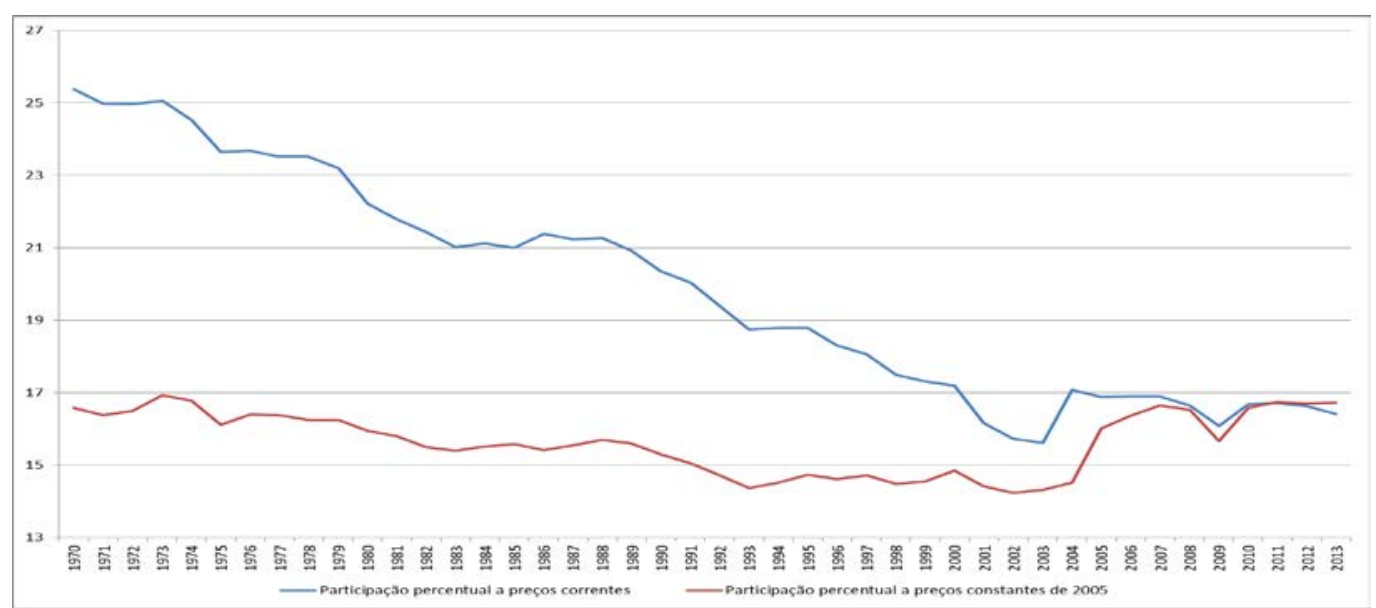

Fonte: Elaboração própria a partir dos dados da UNdata.

O Gráfico 03 demonstra que apesar do processo de desindustrialização em curso afetar tanto os países centrais quanto os periféricos, a China, por exemplo, tem sido exemplo de pais cujo processo não se faz observar. Pelo contrário, parte da desindustrialização ocorrida na Europa e Estados Unidos tiveram como fiel depositária a China e demais países do leste asiático, cuja oferta de mão de obra compreende um dos fatores pelos quais a região tem apresentado taxas expressivas de crescimento (SARTI e HIRATUKA, 2011; CANO 2012).

Gráfico 3: Participação nas Exportações mundiais de bens manufaturados, 1960 - 2014 (\%). 


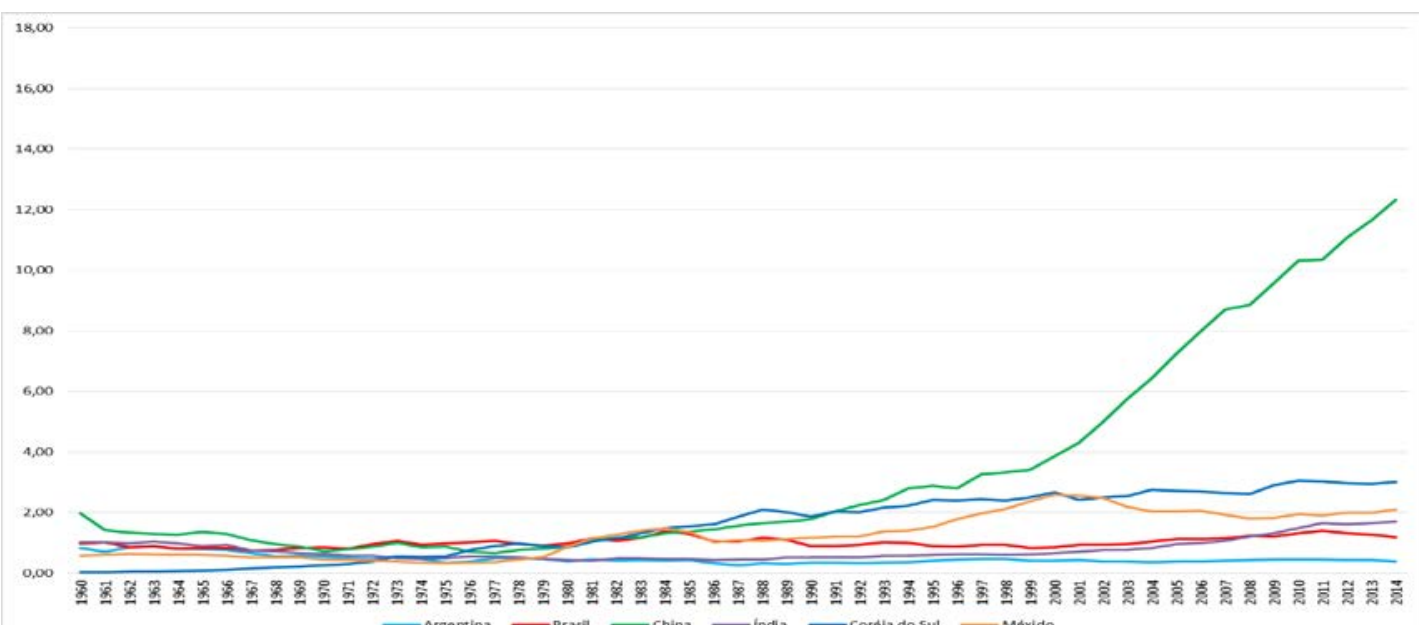

Fonte: World Bank Data. Adaptado e atualizado de Arend (2014).

A partir de meados da década de 80 a China, que detinha $0,62 \%$ das exportações mundiais de manufaturados, alcançou em 2014 uma participação de 16,35\%. Destaque deve ser dado para a Coreia do Sul e México que avançou de 1,45\% em 1985 para 2,55\% em 2014 e 0,62\% para 2,32\% em 2014, respectivamente. O Brasil sofre paulatinamente perda de participação no mercado mundial de exportação de manufaturados desde meados da década de 80, passando de 0,95\% em 1985 para 0,58\% em 2014.

O ciclo de prosperidade de muitos países latino americanos iniciado em meados da década de 2000 apresentou forte relação com a questão do tipo de investimento e dos preços das commodities, cujo resultado impactou fortemente a balança comercial de diversos países, como é o caso do Brasil, e suscitam debates sobre em que condições tem ocorrido o processo de desindustrialização. A partir de 2003, os preços das commodities minerais, produtos agrícolas apresentaram forte elevação até a crise de 2007/2008, para logo em seguida apresentar novo boom até 2011 como pode ser visto pelo Gráfico 04.

Gráfico 4: Índice de preços das commodities, 1980 a 2014 (base = 2010).

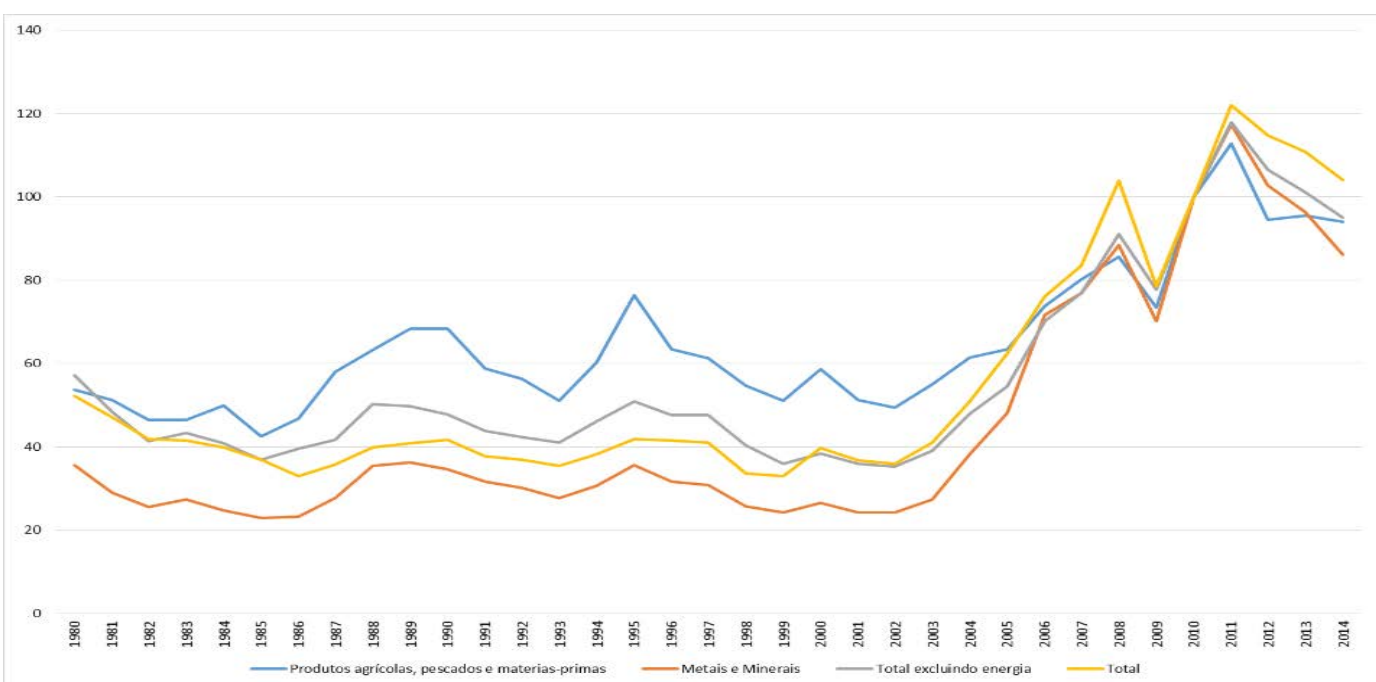

Fonte: Elaboração a partir de dados da CEPALSTAT.

O ponto central aqui exposto é que fatores externos, aqui no caso o boom das commodities, também contribuem para explicar o comportamento da indústria nacional, tanto no que tange a questão da doença holandesa explicada por Bresser-Pereira (2009) da Escola da FGV, quanto do problema da especialização regressiva de Laplane e Sarti (2006) da Escola de Campinas. Além da Escola da PUC- 
Rio/Casa das Garças que considera serem as commodities não necessariamente uma maldição, conforme exposto por Lazzarini, Jank e Inoue, (2013) e Malan (2013).

Enquanto a América Latina apresenta um quadro de IDE voltado para setores agrícola e de serviços, permeado pela elevação dos preços da commodities afetando diretamente sua indústria de transformação, o processo de desindustrialização das economias avançadas pode ser entendido como “natural”, devido ao fato que a participação percentual da manufatura no PIB cai abaixo de $25 \%$ do PIB, e de forma sustentada, quando o nível de renda per capita situava-se ao redor de US\$ 20 mil, como aponta Arend (2014) e pode ser visto pelo Gráfico 05.

Esse é o caso da Europa e dos Estados Unidos que começaram a apresentar perda de participação da indústria no PIB por volta de década de 70, mas com crescimento da renda per capita que atinge, em 2013, valores em torno de US\$ 30 mil e US\$ 40 mil anuais, respectivamente. Isso mostra que mesmo diante de um quadro de perda de importância da indústria na geração de riqueza, as economias desenvolvidas conseguem ampliar a renda per capita, seja pela remuneração mais elevada do trabalhador que permanece na indústria em função de demandar mais conhecimento técnico-científico, seja pela migração de parte da força de trabalho para o setor de serviços vinculados à indústria, os chamados serviços industriais ou serviços intermediários.

Gráfico 5: Comportamento do PIB per capita (preços constantes de 2000, US\$) e valor adicionado manufatureiro, 1970-2013 (\% do PIB).

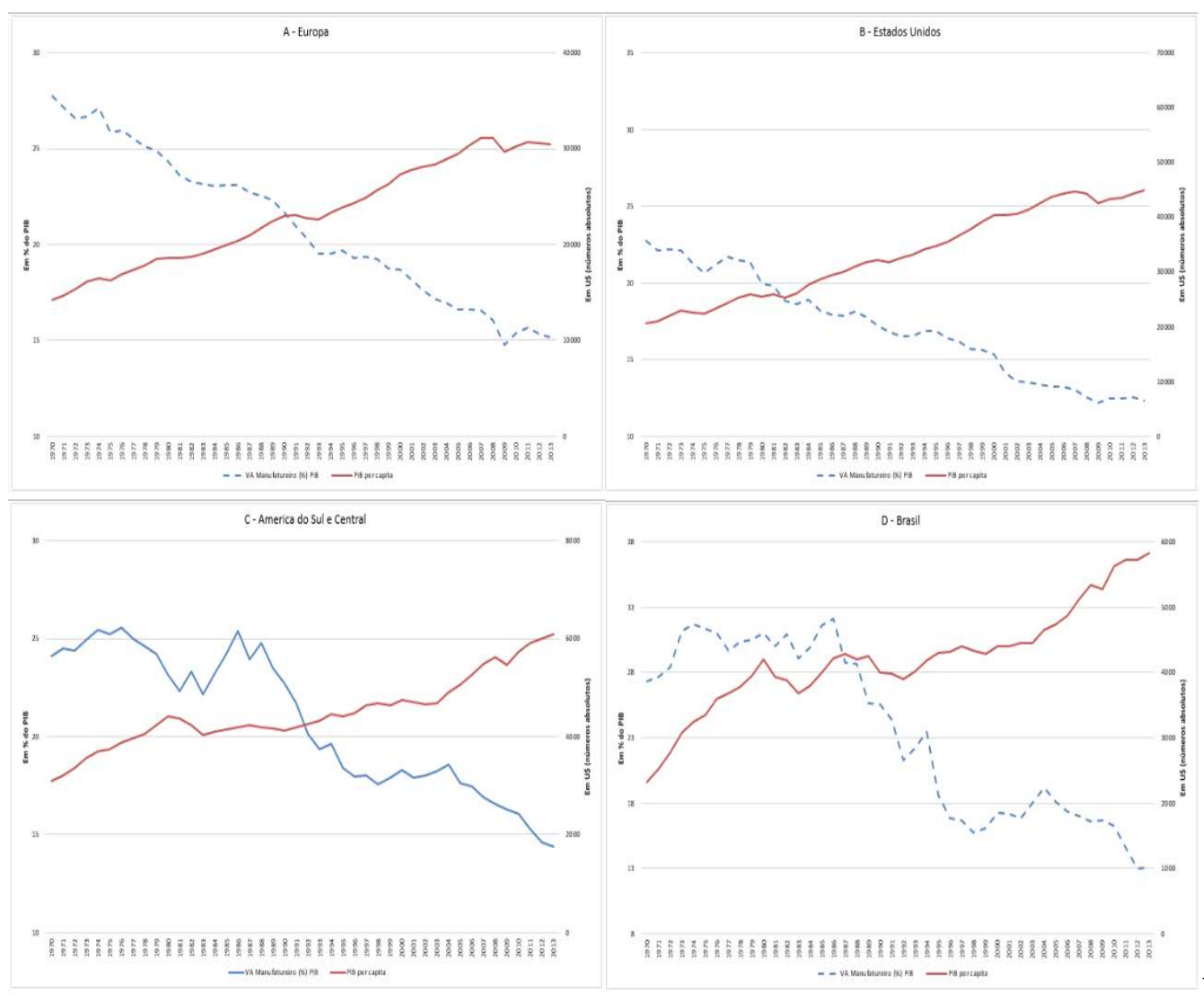

UNCTADSTAT a partir de AREND (2014) e atualizado até 2013.

Fonte:

Nesse sentido, entende-se que a indústria nos países que compõem estas economias, já cumpriu suas funções básicas, possibilitando o setor de serviços assumir a posição de absorvedor e gerador de renda relativa na sociedade dos países centrais. A indústria ao elevar a sua taxa de produtividade, muito 
em função da competição externa, promove o deslocamento de parte da força de trabalho para fora de suas operações diretas, e a abre espaço para a reorganização das etapas de produção ao incluir os serviços como um dos fatores do processo produtivo (RAMASWAMY, 1999; TREGENNA, 2009).

No caso da América Latina e Brasil, observa-se que a partir do processo de desindustrialização, nenhum país selecionado, conseguiu duplicar seu PIB per capita, de modo que a evolução do nível de renda per capita destas economias foi, em grande parte dos casos, inferior ao dos países avançados (AREND, 2014). Para o caso do Brasil e da América Latina, a perda de participação da indústria tem início em meados da década de 80, e a renda per capita em 2013 alcançou valores aproximados de U\$ 6 mil para ambos país e região.

Nestas circunstâncias, a desindustrialização brasileira é precoce, e o país vem se destacando no processo de desindustrialização, tanto em intensidade dentro da América Latina, quanto no sentido do movimento dentre os países em desenvolvimento. O Gráfico 06 mostra a Desindustrialização Relativa Internacional - DRI do Brasil e de um conjunto de regiões e grupos de países selecionados, sendo que o eixo vertical à esquerda corresponde às economias que evoluíram para uma DRI menor que 1, ou seja, que se desindustrializaram em relação ao mundo, e o eixo vertical à direita corresponde às economias que tiveram uma DRI maior que 1 e que, portanto, se industrializaram em relação ao mundo (AREND, 2014).

Nesse sentido, constata-se que o Brasil está na contramão das economias em desenvolvimento e dos novos países industrializados - NICs, pois apresentou em 2013 um DRI correspondente a 61\% do desempenho da indústria mundial. Constata-se, portanto, um DRI maior que o da África em desenvolvimento que correspondeu a 93\%, das economias desenvolvidas que apresentaram um DRI de 70\% e das Américas do Sul e Central que atingiram 74\% no DRI. Países como a China, e aqueles que compreendem os NICs de primeira geração (Taiwan, Singapura, Coreia do Sul e Hong Kong) e NICs de segunda geração (Indonésia, Malásia e Tailândia) apresentaram índices progressivamente crescentes. O destaque da Ásia é a China que vem apresentando desde 90 valores cada vez mais elevados, atingindo em 2013 índice de industrialização de 12,38\%. Os NICs de primeira e segunda gerações atingiram percentuais de industrialização de 3,43\%, e 3,70\% respectivamente, demonstrando a capacidade de geração de riqueza pela indústria.

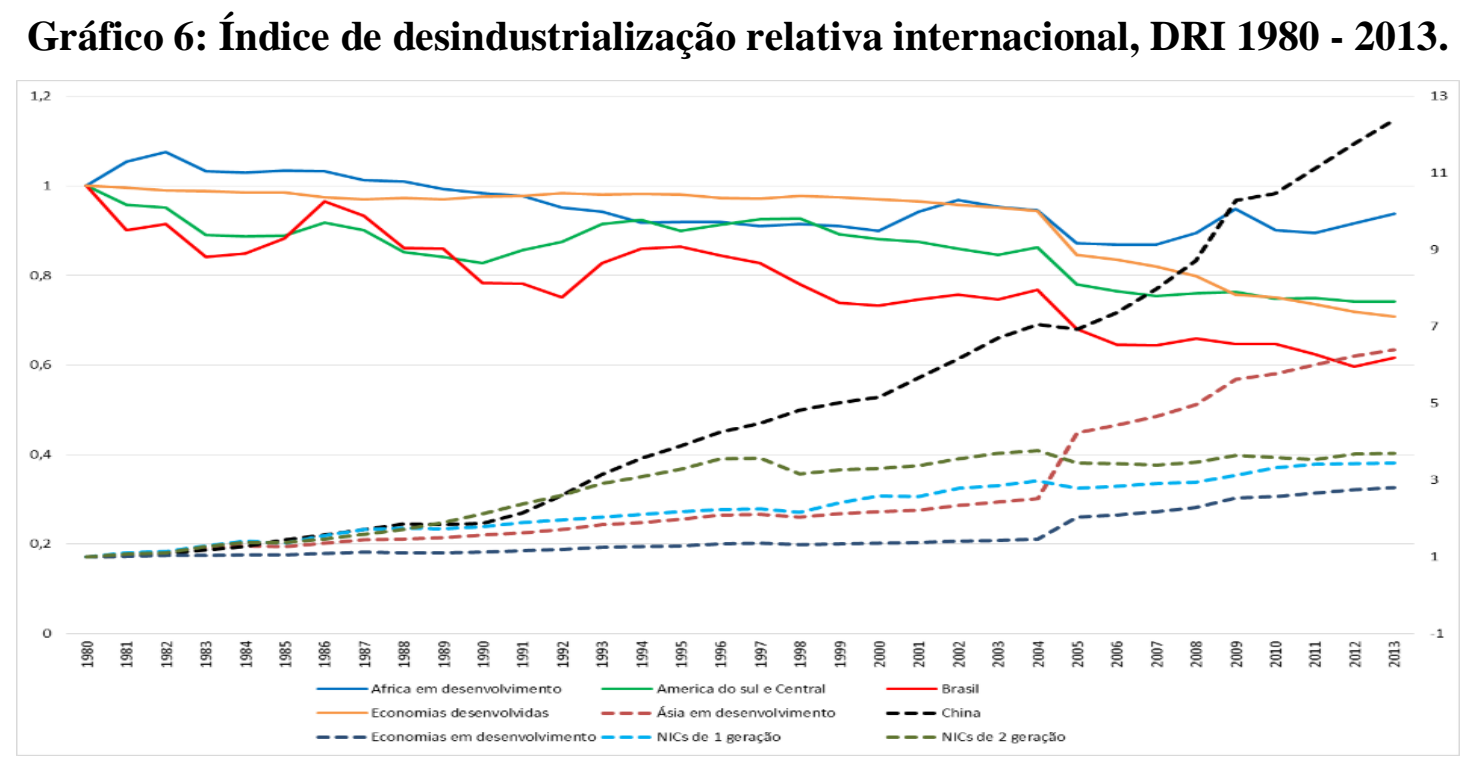

Fonte: UNCTADSTAT a partir de metodologia de Arend (2014). DRIs construídos a partir do IVI em US\$ constantes de 2005. Para mais detalhes ver o subitem 1.4.

Assim, o comportamento da indústria de transformação mundial tem apresentado duas vertentes básicas, a saber: a) a primeira marcada pela desindustrialização natural e precoce, sendo esta última muito 
relacionada aos países com presença de recursos naturais abundantes, como é o caso das nações latino americanas, e b) se enquadram os países asiáticos, cuja dinâmica de industrialização tem se mantido na região através da incorporação de países circunvizinhos como é o caso dos NICs de primeira e segunda geração. O Brasil se enquadra na condição de país com desindustrialização precoce, cujo resultado é a ampliação do gap em relação aos asiáticos deparando com a limitação do crescimento da renda per capita e absorção do progresso técnico.

\section{A industrialização precoce do Brasil - evidência empírica}

A trajetória da indústria brasileira apresentou basicamente duas tendências, a saber: 1) O período que compreende a década de 30 até fins da década de 70 quando o Brasil passou a adotar um modelo de desenvolvimento centrado na substituição de importações, onde uma série de esforços foram empreendidos no sentido de formar no território nacional um parque industrial sofisticado e suficientemente maduro, capaz de sustentar taxas consistentes de crescimento do produto nacional. Destacam-se nessa fase o projeto varguista, do desenvolvimento nacionalista, passando por JK com o desenvolvimentismo associado ou internacionalista, e o período militar com o "Projeto Brasil Grande Potência”. A indústria brasileira e o capital internacional, que se estabeleceu no Brasil, obtiveram uma série de vantagens visando estimular sua fixação, crescimento e constituição de laços produtivos com os capitalistas nacionais (MACARINI, 2000; 2005; 2008, AREND, 2009).

2) O período que compreende meados da década de 80 até o presente, cujos estudos tem evidenciado a perda de participação do PIB industrial no PIB agregado, queda de produtividade e perda de postos de trabalho (BRESSER e MARCONE, 2008; SOARES, OREIRO e TEIXEIRA, 2013). Assim, este subitem focou nesta segunda tendência, e procurou avaliar a situação da indústria de transformação brasileira à luz das escolas de pensamento. O Gráfico 07 apresenta a evolução da participação da indústria de transformação no PIB e o grau de abertura da economia.

\section{Gráfico 07: Participação do PIB da Indústria de Transformação no PIB nacional e Grau de Abertura da economia, 1947-2013 (\%).}

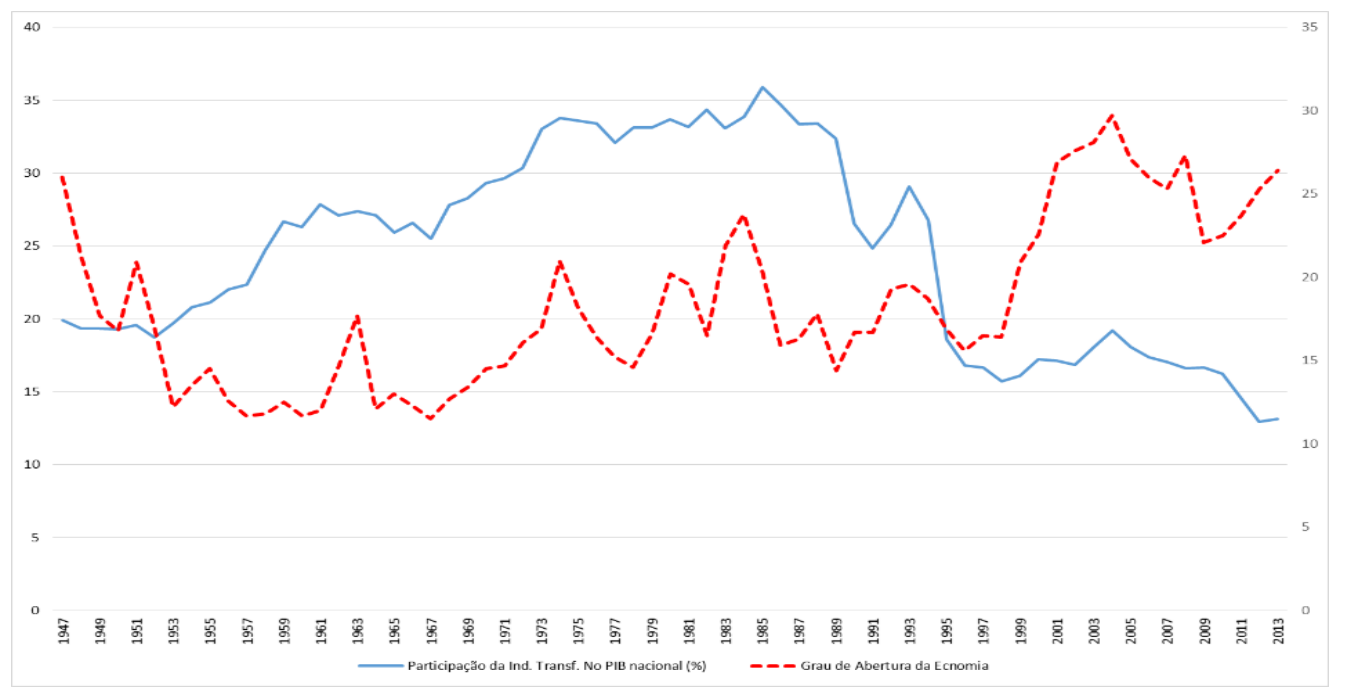

Fonte: elaborado a partir dos dados coletados no IPEADATA.

Observa-se que durante o período de menor abertura da economia brasileira, aproximadamente de 1953 a 1984, a indústria de transformação alcançou participações continuamente elevadas na formação do PIB, o que nos remete às considerações de formulação de política econômica da CEPAL no que tange a 
proteção à indústria infante, bem como os estímulos à economia na década de 70. Entretanto, a partir de 1985 observa-se um processo de perda de participação sistemática da indústria de transformação, mesmo ainda sob condições de uma economia relativamente fechada. O período de ampla abertura econômica da segunda metade da década de 90 viria agravar ainda mais a participação da indústria no PIB brasileiro.

A década de 80 é extremamente importante para entender a dinâmica atual da indústria brasileira. Também chamada de década perdida, conforme Carneiro (2002), caracterizada pela crise da dívida com piora dos termos de troca comercial e extremo racionamento do financiamento externo, o que significou a transferência de recursos externos para o exterior em razão do pagamento da dívida externa. Segue-se também, a fragilidade do setor público pelo endividamento interno e perda de dinamismo do setor produtivo estatal. Carneiro (2016) aponta a combinação de três fatores em intensidades distintas para explicar o encarecimento do investimento: a desvalorização real do câmbio, o aumento da taxa de juros e os ciclos econômicos recessivos.

Além dos fatores conjunturais, Suzigan (1991) aponta que a estrutura industrial brasileira foi construída ao amparo de políticas que sucessiva e cumulativamente propiciaram níveis elevados de proteção à indústria no mercado interno. $\mathrm{O}$ apoio ao desenvolvimento tecnológico foi limitado à aquisição de capacidade para produzir, embora nos anos 70 já se tivesse iniciado a implantação das bases institucionais. Em resultado em fins de 70, e princípios dos 80, a estrutura industrial brasileira apresentava elevados graus de integração intersetorial e de diversificação da produção, porém, com insuficiente desenvolvimento tecnológico, ineficiências técnicas e econômicas específicas que limitavam sua competitividade, ausência de qualquer padrão nítido de especialização, e pouca integração com o mercado internacional. (SUZIGAN, 1991)

Pode-se considerar que as tendências mais marcantes para o setor industrial no período da década de 80 são: 1) a inversão da tendência e a perda de dinamismo do padrão de desenvolvimento anterior à crise dos anos 80 sem a conformação de um novo padrão; 2) redução da produção para o mercado interno com aumento do coeficiente de exportação e redução do ritmo de aumento da produtividade; 3) a retração dos investimentos, e; 4) limitação dos esforços de incorporação de progresso técnico, com ampliação do hiato tecnológico e acentuação da heterogeneidade tecnológica intersetorial, bem como desequilíbrios da estrutura produtiva da indústria e da infraestrutura econômica e social (SUZIGAN, 1991).

Essa trajetória pode explicar em muito o esboço de reação da indústria observada até 1993, mas o processo de abertura econômica de 1998 até 2004 sugere ter agravado mais ainda a perda de participação da indústria de transformação, muito embora o período de 2004 até 2013 de reversão da abertura econômica não tenha conseguido reverter o processo de perda de participação da indústria no PIB. Nesse sentido, como aponta a escola de Campinas a abertura, econômica agrava o processo de desindustrialização já em curso desde meados da década de 80. Entretanto, é importante ressaltar que mesmo com o fechamento da economia durante o período de 2004 a 2009 não foi observado a capacidade por parte da indústria de transformação em reverter o quadro de definhamento da indústria nacional, sugerindo evidentemente a existência de outros fatores responsáveis pela perda de força da indústria nacional. 
Gráfico 08: Participação do produto manufatureiro do Brasil no produto manufatureiro mundial, 1970 - 2013 (\%).

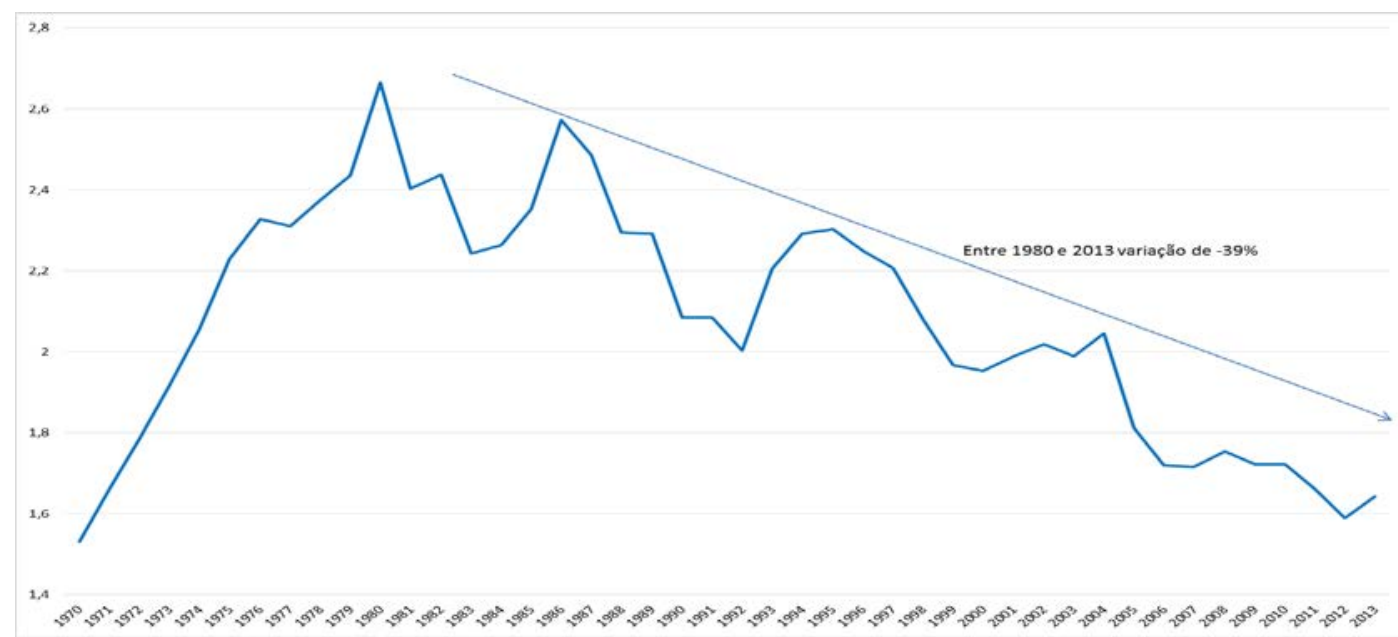

Fonte: Arend (2014) a partir de UNCTADSTAT. Valores atualizados para 2013 em U\$ constantes de 2005.

Como resultado desta perda de participação da indústria de transformação no PIB, Arend (2014) e Sampaio (2015) apontam que em relação ao total mundial, o pico de participação da indústria de transformação brasileira ocorreu por volta de 1980, quando obteve 2,68\%, sendo que o segundo ano com maior participação foi em 1986 2,58\%, e que a partir de então, deu-se início uma queda acentuada, de modo que em 2012 o valor foi de 1,62\%.

Em decorrência desse processo, evidencia-se uma queda de aproximadamente 39\%, só no período de 1980 a 2013, da participação do produto manufatureiro brasileiro em relação ao produto manufatureiro mundial, isto é, a desindustrialização do Brasil internacionalmente tem se apresentado de forma sistemática e bem acentuada, ao longo de trinta anos. A questão da importância da indústria de transformação pode ser analisada pelo Gráfico 08 que mostra as oscilações do PIB da indústria de transformação e do PIB global da economia entre 1983 e 2013.

As oscilações da taxa de variação real do PIB da indústria de transformação tendem a ser mais agudas que as oscilações do PIB nacional, muito embora, o comportamento deste não se descole completamente do comportamento do PIB da indústria. O diferencial nas oscilações se devem ao comportamento, tanto do setor agrícola quanto do setor de serviços que minimizam este impacto, mas a questão mais importante aqui posta é que as oscilações sugerem que o PIB brasileiro segue comportamento idêntico ao comportamento da indústria de transformação. Isto posto, apesar do setor industrial estar perdendo participação no valor adicionado, exerce ainda influência na dinâmica econômica visto pela correlação positiva entre ambos os PIBs.

Torna-se relevante considerar dois elementos importantes que se encontram na base do processo produtivo e ajudam a entender o quadro atual da produção industrial, a saber: 1) o investimento, e 2) a quantidade produzida como função não só do investimento, mas do tipo de investimento. A evolução percentual do investimento por grupos setoriais, segundo Gráfico 09 aponta que a indústria do petróleo ganhou nos últimos quatorze anos participação considerável no total do investimento global, de $11 \%$ em 1996 para 37\% em 2010. Enquanto, os demais setores apresentaram progressiva queda nos investimentos, com destaque para aqueles ligados à média alta e alta intensidade tecnológica que passam de aproximadamente 35\% em 1996 para 18\% em 2010. 
Gráfico 09: Taxas de variação real anual do PIB nacional e do PIB da indústria de transformação do Brasil, 1983 - 2013 (\%).

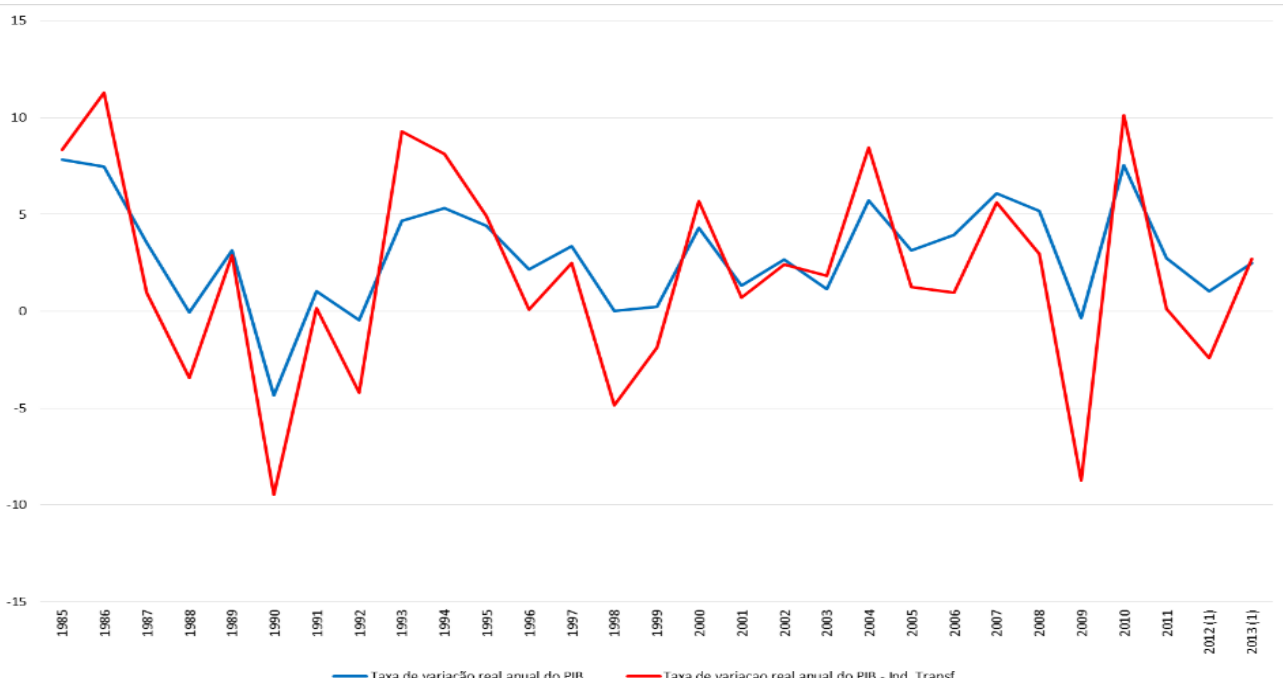

Fonte: IBGE. Os anos de 2012 e 2013 são estimados.

Gráfico 10: Evolução do investimento nacional na indústria extrativa e de transformação, 1996 2010 (\%).

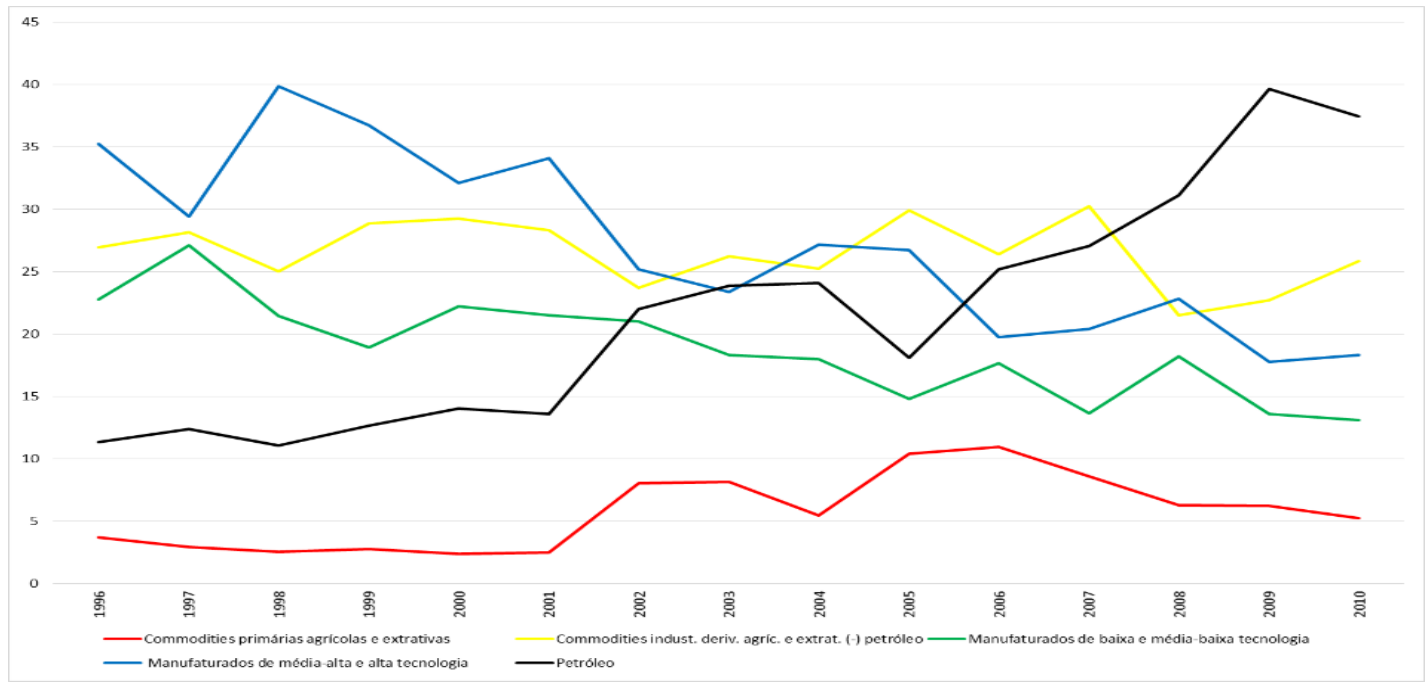

Fonte: Arend (2014) originado da PIA elaborado pelo Centro de Macroeconomia Estruturalista do Desenvolvimento - CEMACRO.

Nesse sentido, ao longo de uma década e meia os investimentos industriais têm se concentrado nas áreas ligadas ao petróleo, e às commodities primárias agrícolas e extrativas, conforme o Gráfico 10, corroborando as colocações de Laplane e Sarti (2006) bem como as análises de Coutinho (1997), sobre a tendência ao deslocamento dos investimentos em setores de baixa tecnologia, e produtos primários, cujo resultado, pode ser entendido como um processo de especialização regressiva da economia brasileira. Tal ocorrência se manifesta em correspondência com as proposições de Arend (2009) e Arend e Fonseca, (2012), ao constatarem a existência de um processo gradual de falling behind na economia brasileira. 
Gráfico 11: Î́ndice da produção física industrial, quantum 1996 - 2013, (média 2002 = 100).

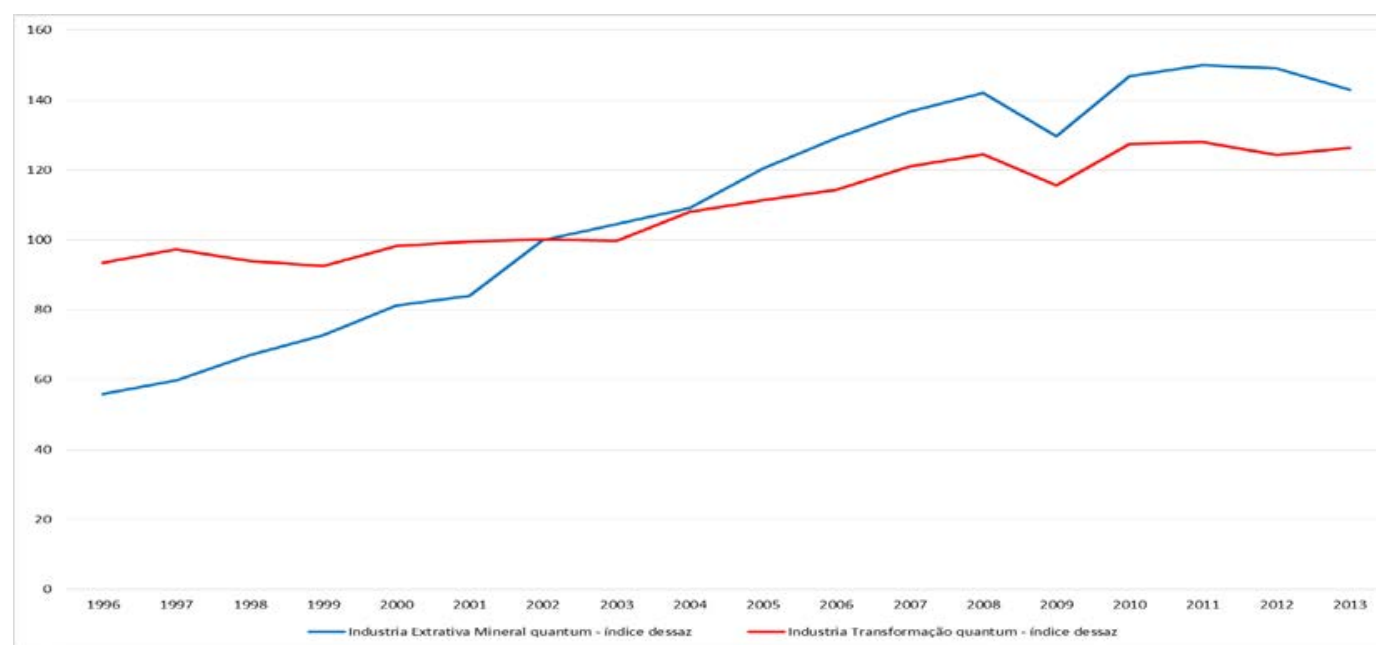

Fonte: Elaboração própria a partir de PIA/IBGE

O resultado da trajetória do investimento pode ser observado na elevação do quantum produzido pela indústria extrativa, e da indústria de transformação. A trajetória da produção física de ambas indústrias, como aponta o Gráfico 11, apresentou desde 1996 taxas crescentes, entretanto, a partir do ano 2000 a produção física da indústria extrativa ultrapassou a produção da indústria de transformação, chegando em 2013 com um diferencial de aproximadamente 17\% entre ambos.

Tabela 1: Investimento Direto Externo - IDE - por setor de atividade - Brasil - US\$ milhões, 1996, 2000, 2005, 2010 e 2014 (\%).

\begin{tabular}{l|cc|cc|cc|cc|cc}
\hline & \multicolumn{2}{|c|}{1996} & \multicolumn{2}{c|}{ 2000 } & \multicolumn{2}{c|}{ 2005 } & \multicolumn{2}{c|}{ 2010 } & \multicolumn{2}{c}{$\mathbf{2 0 1 4}$} \\
\cline { 2 - 10 } & Fluxo & $\%$ & Fluxo & \% & Fluxo & $\%$ & Fluxo & \% & Fluxo & \% \\
\hline Agric., pecuária e extrat. mineral & 110,58 & 1,44 & 649,44 & 2,17 & $2.194,37$ & 10,20 & $16.260,98$ & 29,39 & $5.620,54$ & 8,89 \\
Indústria & $1.740,02$ & 22,70 & $5.070,18$ & 16,97 & $6.402,81$ & 29,75 & $21.272,75$ & 40,49 & $16.919,83$ & 30,46 \\
Serviços & $5.814,89$ & 75,86 & $24.156,75$ & 80,86 & $12.924,38$ & 60,05 & $14.702,50$ & 29,65 & $33.310,69$ & 59,89 \\
Total & $7.665,49$ & 100 & $29.876,37$ & 100 & $21.521,57$ & 100 & $52.583,34$ & 100 & $56.050,15$ & 100 \\
\hline \hline
\end{tabular}

Fonte: Relatório do Banco Central - vários anos.

Depreende-se que mais do que a perda de participação da indústria no PIB advinda da baixa produtividade, ou de fatores macroeconômicos adversos, bem como do simples fechamento de plantas produtivas, deve-se ter em mente que tem existido uma estratégia privada de realocação do investimento em setores tradicionais que reforça a desindustrialização. A demanda externa contribui para conformar um padrão de inserção internacional ligado ao fornecimento de produtos primários, cujos os preços das commodities têm afetado a decisão dos investimentos tanto domésticos, quanto internacionais.

Analisando-se o IDE entre 1996 e 2014 observa-se que o fluxo de investimento varia conforme a conjuntura econômica e por consequência a rentabilidade do investimento. A Tabela 01 mostra que as atividades ligadas ao setor de agrícola e de extração mineral apresentou elevação contínua ao longo de dezoito anos com crescimento de aproximadamente 8 p.p. O setor industrial apresentou crescimento do investimento até 2010, muito influenciado pelas taxas elevadas de crescimento da economia brasileira após 2006, mas já em 2014 observa-se retração de 10 p.p..

Conforme apontado anteriormente, o debate sobre o comportamento da indústria brasileira tem demonstrado que esta, vem apresentando ao longo das últimas décadas um comportamento diferente, em relação ao período da década de 30 até meados da década de 80. Observando o Valor bruto da produção industrial - VBPI e o Valor da transformação industrial - VTI da indústria brasileira nos últimos dezoito anos, por meio de grupos de intensidade tecnológica (Alta, Média-alta, Média-baixa e Baixa) analisa-se o 
comportamento da indústria, quanto a capacidade de geração de valor, estrutura dos elos da cadeia produtiva, e o nível de produtividade.

De posse da participação do VBPI, Gráfico 12, por intensidade tecnológica, observa-se que os setores de baixa intensidade tecnológica responderam por mais de 35\% do valor bruto total da economia brasileira, e ao longo do período analisado, salvo as oscilações conjunturais, manteve-se praticamente estável fechando o ano de 2013 com praticamente 35\% de participação contra 36\% de participação em 1996. Os setores de alta intensidade tecnológica ampliaram sua participação ao longo dos dezoito anos, alcançando em 2013 cerca de 6\% da participação total com um crescimento percentual de aproximadamente 170\%, para o último ano da série analisada, tendo como referência o ano de 1996.

Importante ressaltar que os setores de média alta intensidade tecnológica, a partir de 2009, passaram a superar os setores ligados à média baixa intensidade tecnológica, sugerindo ser esta, uma trajetória que se sustente a médio e longo prazo caso a economia brasileira não venha sofrer crises agudas e prolongadas. Estas atividades apresentaram em 2013, crescimento de aproximadamente 83\% atingindo a segunda colocação em relação aos setores de alta intensidade tecnológica.

Considerando o VTI, Gráfico 12, percebe-se que os setores de baixa intensidade tecnológica, mantiveram certa estabilidade ao longo do tempo, excetuando o período de 2009 a 2013, período este em que ocorre ampliação de sua participação no VTI total da indústria. Os setores de média baixa intensidade tecnológica apresentaram perda de 4 p. p. entre 2008 e 2009 mantendo e mantendo assim sua participação em torno de $30 \%$.

Além disso, cabe atenção ao fato de que os períodos 2000/2003 e 2008/2009 correspondem aos anos de forte instabilidade econômica, mas que em termos de evolução do VTI, a crise de 2008 e 2009 não afetou com grande intensidade os setores de baixa intensidade tecnológica e alta intensidade tecnológica, a ponto de alterar substancialmente as respectivas trajetórias de sua evolução no tempo. Para tanto, o VTI dos setores de alta intensidade tecnológica alcançara o ano de 2013 com cerca de $98 \%$ de crescimento em relação ao ano de 1996. Outro ponto relevante a ser considerado, é que o setor de média alta intensidade tecnológica chegou ao final do período analisado como o terceiro maior VTI (45\%), sugerindo estar em curso, ainda que lentamente um processo de transformação da economia brasileira.

\section{Gráfico 12: Evolução por intensidade tecnológica do Valor Bruto da Produção Industrial (VBPI) - A e Valor da Transformação Industrial (VTI) - B - Brasil, 1996 - 2013, número índice (1996 = 100).}

A

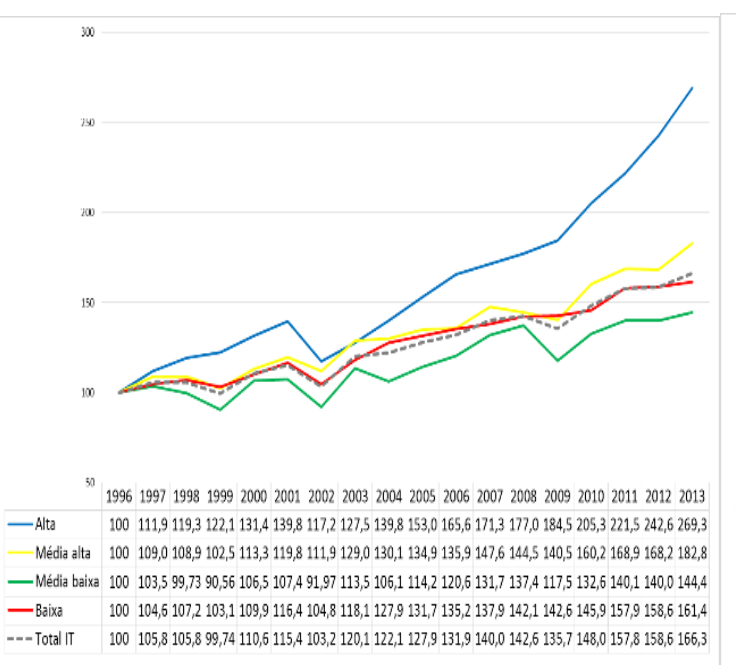

B

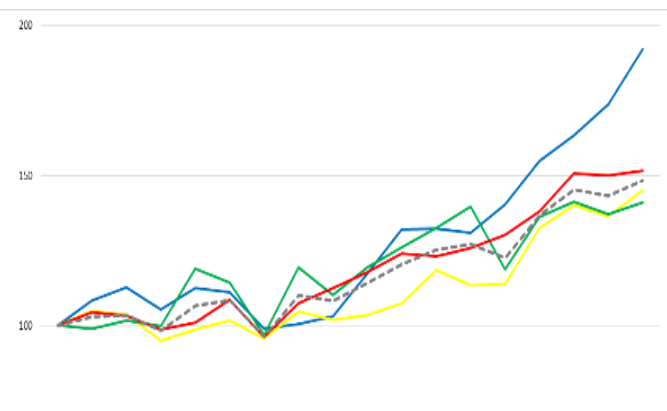

50 199619971998199920002001200220032004200520062007200820092010201120122013 $100108,3112,7105,4112,4111,1$ 98,9 100,5 103,2 $117,3132,0132,4130,9140,3154,9163,5173,7192,1$ alta $\quad 100104,9103,795,098,7101,795,7104,6102,0103,6107,5118,4113,5113,9132,7140,2136,4145,1$ xa $100 \quad 98,9101,7100,0118,9114,496,9119,5110,2119,4126,1132,6139,8118,9136,2141,2137,1141,0$ $100104,4103,398,6100,9108,696,1107,5112,5117,8124,1123,2125,9130,3138,2150,7150,0151,7$ 100 103,0 103,4 98, 106,6 108,696,4 110,2 108,3114,2 120,4 125,3 $127,0122,4$ 136,8 145,3 143,2 148,4

Fonte: Elaboração própria a partir de dados da PIA-IBGE e classificação OCDE (2011). 
Gráfico 13: Participação dos grupos por intensidade tecnológica do Valor Bruto da Produção Industrial (VBPI) - A e Valor da Transformação Industrial (VTI) - B - Brasil, 1996 - 2013, (\%).

A

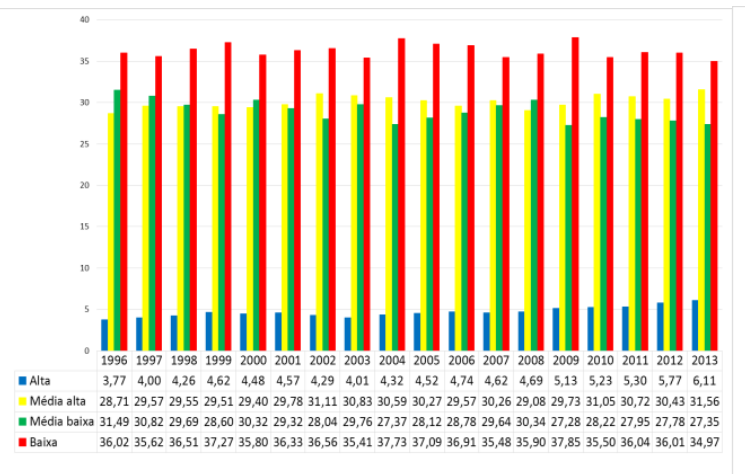

B

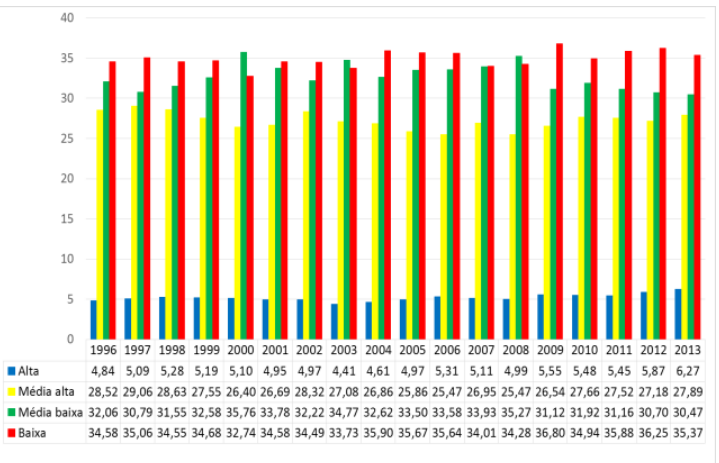

Fonte: Elaboração própria a partir de dados da PIA-IBGE e classificação OCDE (2011).

Nota: Série deflacionada pelo IPEA-OG da FGV a preços de 2013.

Da análise dos Gráficos 12 e 13, pode-se constatar que todos os setores por intensidade tecnológica apresentaram crescimento ao longo do período, com destaque para o grupo de alta intensidade tecnológica. Os dados sugerem que não se encontra em curso no Brasil um processo de desindustrialização absoluta, como pode ser observado pelo comportamento do valor da transformação industrial e o valor bruto da produção industrial. A trajetória das intensidades tecnológicas sugere que o Brasil vem apresentando um comportamento que não indica concentração em setores de baixa intensidade tecnológica, muito embora no caso do VTI os setores de baixa intensidade mantiveram taxas de crescimento relativamente persistentes. A participação percentual do VTI por grupos de intensidade tecnológica aponta que os setores de baixa e média baixa intensidade tecnológica não apresentaram perda de participação significativa ao longo do tempo. Os setores de média alta e de alta intensidade tecnológica obtiveram participação relativa pequena no VBPI e VTI da indústria de transformação.

Gráfico 14: Razão entre Valor da Transformação Industrial (VTI) e Valor Bruto da Produção Industrial (VBPI) por intensidade tecnológica - Brasil, 1996 - 2013 (\%)

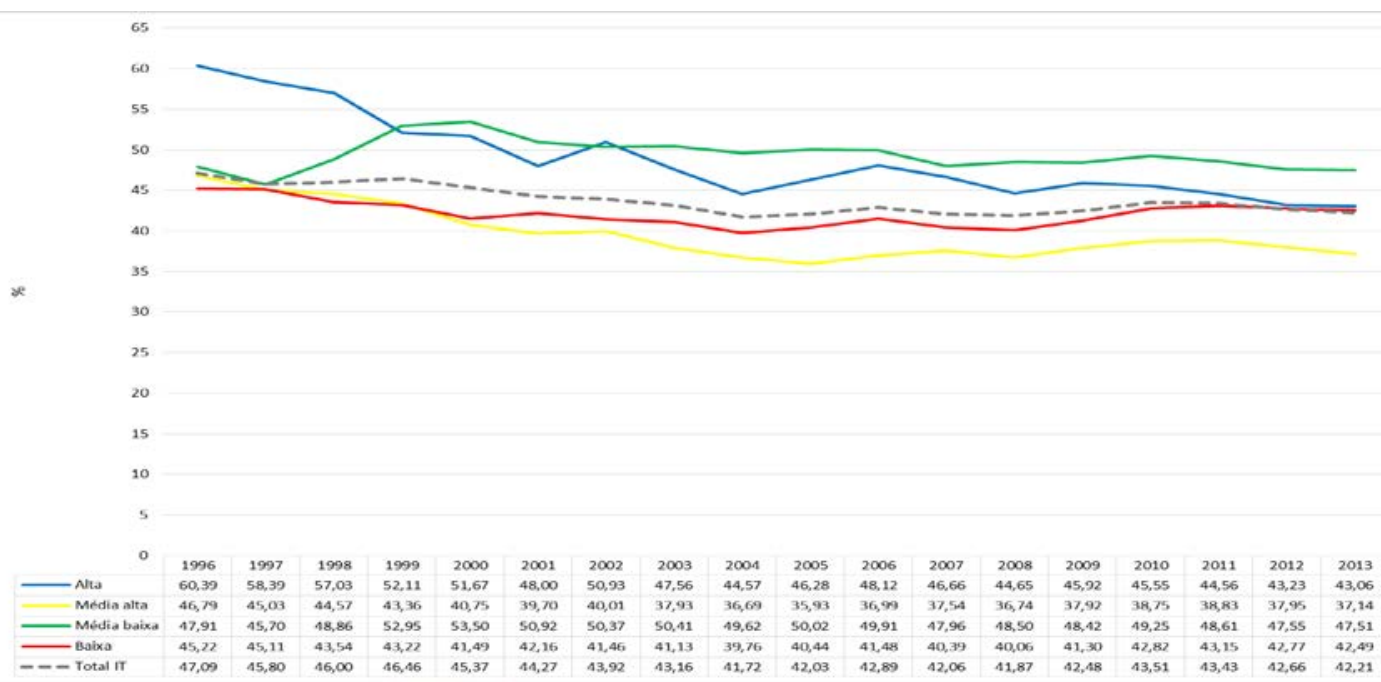

Fonte: Elaboração própria a partir de dados da PIA-IBGE e classificação OCDE (2011).

Nota: Série deflacionada pelo IPEA-OG da FGV a preços de 2013. 
Isto pode ser constatado pelo gráfico 14 que trata da densidade produtiva, como forma de analisar a existência de perda, ou não, de elos da cadeia produtiva. É importante ressaltar que a relação VTI/VBPI permite captar em que medida a indústria brasileira tem gerado valor em relação ao valor vendido, ou de outra forma, diante de uma queda da referida razão pode-se inferir a existência de elevação de conteúdo importado da produção doméstica. Diante disto, percebe-se que todos os setores têm apresentado trajetória de queda da razão VTI/VBPI no período de 1996 a 2013. Com destaque tem-se os setores de alta e média alta intensidade tecnológica que perderam respectivamente 17,3 p.p e 9,65 p.p respectivamente. Em termos agregados a economia brasileira como um todo apresentou queda de seu adensamento produtivo no período de 1996 a 2013 de 4,8 p.p.

A trajetória de queda da razão VTI/VBPI e a análise do VTI e VBPI em conjunto, sugerem que o Brasil tem apresentado perda de elos da cadeia produtiva ao logo de dezoito anos, porém mostra que as unidades industriais que não entraram em processo de falência, se reorganizaram de tal forma que conseguiram ampliar a capacidade produtiva, o que pode estar explicando as taxas crescentes para todos os grupos por intensidade tecnológica do VTI e VBPI.

Outro elemento importante para avaliar a existência, ou não, do processo de desindustrialização reside em avaliar o comportamento do emprego na indústria de transformação. Para tanto, conforme o Gráfico 15, observa-se uma retração da participação do emprego da indústria de transformação no total do emprego formal ao longo dos últimos trinta anos, reduzindo de 27,1\% em 1986 para 16,6\% em 2014. Entretanto, cabe ressaltar que a redução do emprego formal na indústria de transformação pode ser resultado de aumento da produtividade, o que confere atenção especial quando se trata deste tipo de análise. Mas como a produtividade cresceu muito pouco, e a taxa de participação do emprego industrial vem caindo sistematicamente, demonstrando haver evidências de um processo de desindustrialização, como sustentam os estudos de Ramaswamy (1997); Ramaswamy (1998); Ramaswamy (1999) e Tregenna (2009).

Gráfico 15: Participação no emprego formal da Indústria de Transformação - Brasil, 1985 a 2014 (\%).

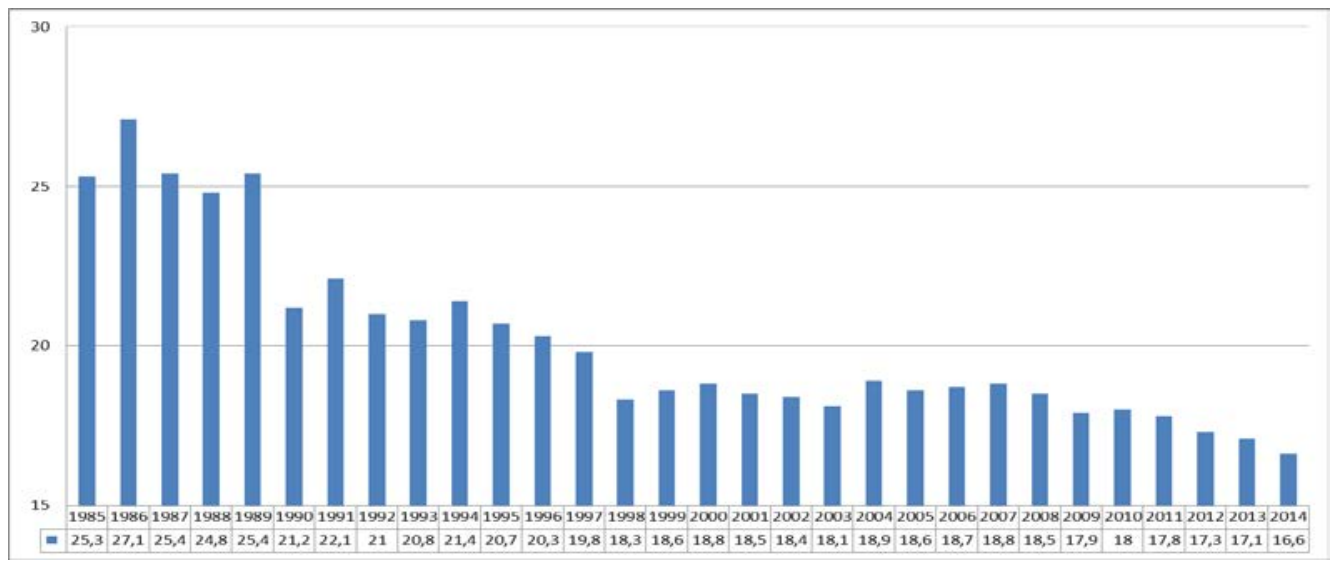

Fonte: Elaboração própria a partir de MTE/RAIS. 
Gráfico 16: Crescimento percentual anual médio da produtividade do trabalho (VA/PO) na Ind. Transformação (2004 a 2012, US\$ preços constantes).

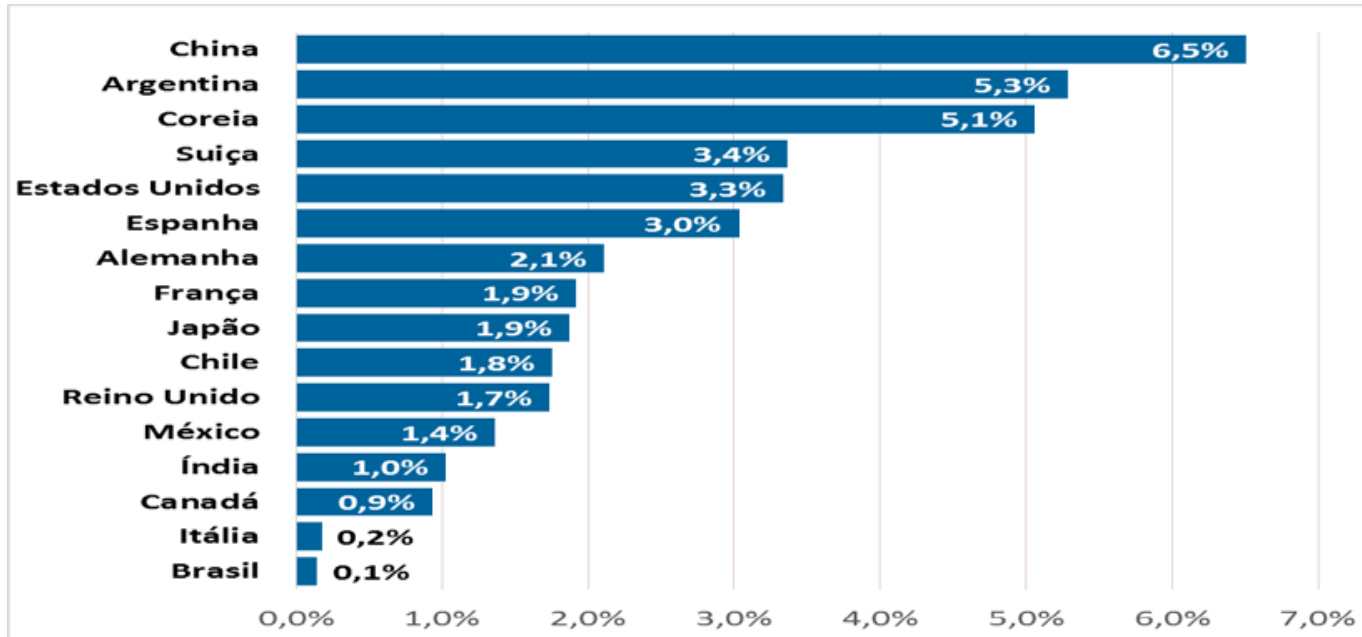

Fonte: adaptado de FIESP, OIT e Banco Mundial.

Analisando-se a produtividade da indústria brasileira, conforme o Gráfico 16, em relação aos demais países, pode-se constatar a grande disparidade existente com relação à China e a Coréia do Sul, que apresentaram 6,5\% e 5,1\% de taxa de crescimento médio anual contra 0,1\% do Brasil ao longo de oito anos. Trata-se da segunda lei que aponta a existência de uma relação positiva entre a taxa de crescimento da produtividade na indústria e o crescimento do produto industrial, sendo a relação de causalidade na direção de quanto maior a taxa de crescimento da indústria, maior será também a taxa de crescimento da produtividade. Em países com desindustrialização natural como os Estados Unidos, França e Reino Unido, com taxas de crescimento médio anual de 3,3\%, 1,9\% e 1,7\% respectivamente, tais percentuais são maiores que a produtividade brasileira, sugerindo ser a natureza da deterioração da indústria nacional muito mais grave e difusa.

Gráfico 17: Saldo da balança comercial por intensidade tecnológica (bilhões R\$) e taxa de câmbio (R\$/US\$) - Brasil, 1997 - 2014.

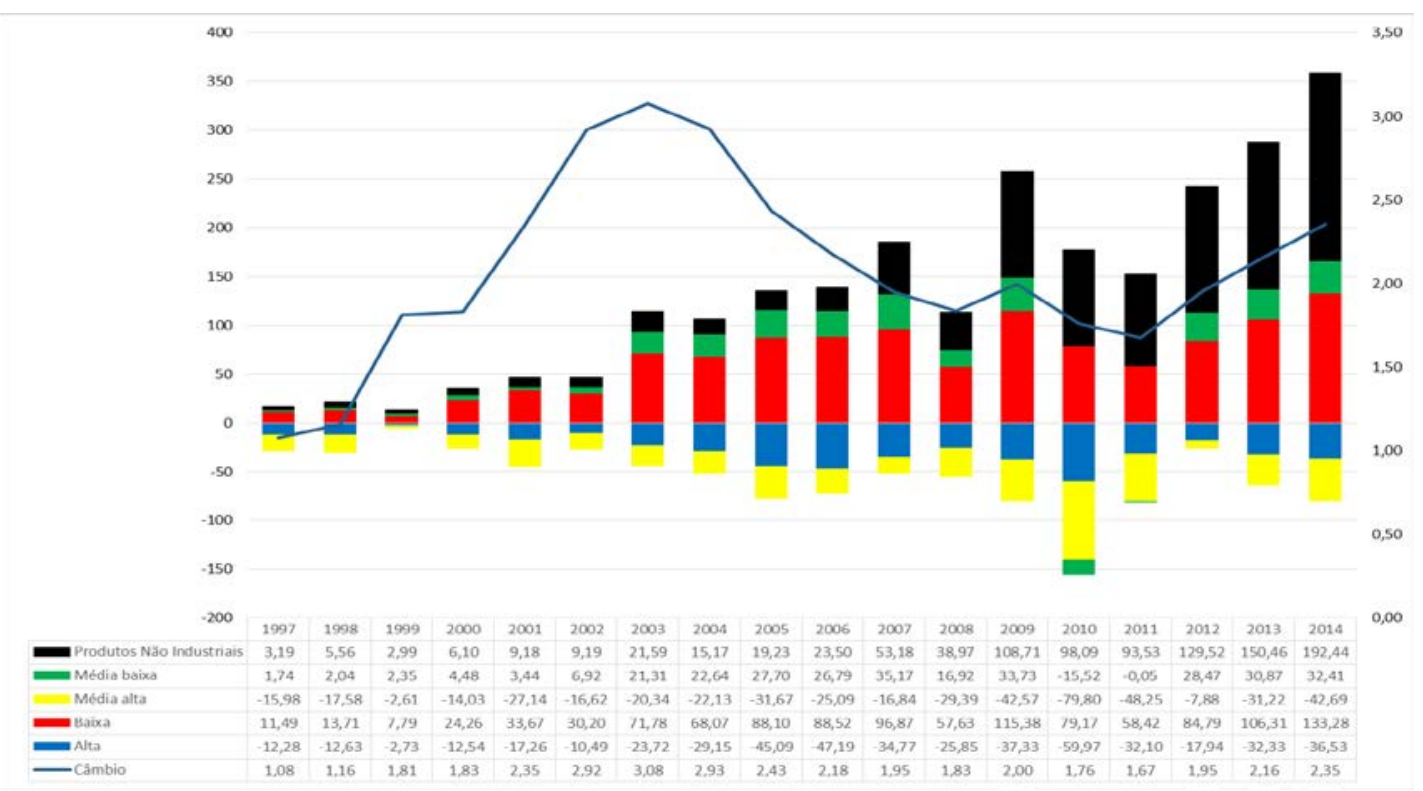

Fonte: Elaboração própria a partir dos dados da COMEX 
A inserção internacional do Brasil é outra dimensão essencial para investigar a existência de desindustrialização na economia brasileira, e possibilita analisar a trajetória da posição relativa do Brasil no comércio mundial. O debate sobre a desindustrialização tem dedicado atenção especial para a variável câmbio como elemento capaz de dinamizar a economia quando bem administrado.

No Brasil o período de 1994 a 1999 foi marcado pelo uso de uma âncora nominal como forma de estabilização dos preços, base considerada para implantação do Plano Real, e uma política monetária restritiva por parte do Banco Central, cujos resultados manifestaram-se em sobrevalorização cambial e elevados déficits na balança comercial. Após a crise russa de 1998 e a expressiva vulnerabilidade do Brasil em decorrência de sua posição enquanto país periférico, passou a adotar o regime de câmbio flutuante, o que contribuiu para a ocorrência de grande volatilidade cambial ao longo dos anos posteriores.

Nesse sentido, observando o Gráfico 17, o saldo da balança comercial brasileira de 1997 a 2014 evidencia-se uma característica clássica da economia brasileira a saber: o déficit recorrente da balança comercial em produtos de alta e média alta intensidade tecnológica. Os períodos de maior apreciação cambial, que corresponderam aos anos de 1997-1998 e 2008-2011, foram aqueles cujos setores de maior intensidade apresentaram maior déficit. As atividades não industriais apresentaram superávits positivos nos períodos de maior apreciação cambial, sobretudo de 2009 a 2014.

\section{À Guisa da Conclusão}

Ao se analisar o Brasil pós meados da década de 80, percebe-se que o deslocamento brasileiro para faixas inexpressivas no quadro de países exportadores de manufaturados, cuja trajetória entre 1984 e 2013 atingiu perda de praticamente 0,5\% ao ano, é reflexo da mudança da dinâmica internacional de capitais que se tornaram mais financeirizadas, da perda de capacidade da indústria nacional em acompanhar a corrida tecnológica internacional, bem como apresenta relação com o grau de abertura da economia brasileira, após meados da década de 90. Os dados corroboraram as colocações de Cano (2012a:2014) Sarti e Hiratuka (2011); Carneiro (2002) e Ferraz (1995) da Escola de Campinas e Bresser Pereira e Marconi (2008) da Escola da FGV, na medida em que a indústria nacional começou a perder vigor no momento em que a economia brasileira passou a ser regida pelos ditames da ideologia neoliberal.

O resultado desse processo de abertura e privatização como descrito por Carneiro (2002) levou a conformação de uma estrutura cristalizada no estágio da terceira e quarta revolução industrial, cuja expressão é a grande participação percentual de setores de baixa e média baixa intensidade tecnológica, que são responsáveis em média por mais de 60\% do VTI e VBPI. Entretanto, importante ressaltar que, para a União Europeia em 2013, os setores de baixa e média baixa intensidade tecnológica responderam por 53\% do valor adicionado total da manufatura (JAEGERS, LIPP-LINGUA, e AMIL, 2013). Esse percentual brasileiro não é tão negativo como parece, porém, o mais relevante a se discutir é a dinâmica produtiva e inovativa de cada grupo por intensidade tecnológica como fator capaz de colocar determinados países na fronteira do desenvolvimento.

Em decorrência da abertura econômica de meados da década de 90, do enfraquecimento do Estado, e das limitações do processo de desenvolvimento tecnológico enfatizado pela Escola de Campinas, bem como diante da existência de doença holandesa por que passa a economia brasileira, como expõe Bresser Pereira da Escola da FGV, o tecido industrial brasileiro (VTI/VBPI) entre 1996 e 2013 apresentou deterioração contínua, conforme pode se depreender do gráfico 19. Os setores de alta e média alta intensidade tecnológica foram os que mais sofreram perdas nas cadeias produtivas sendo respectivamente 61\% em 1996, e caindo para 43\% em 2013 para alta intensidade tecnológica, e 47\% em 
1996 para 37\% em 2013 para média intensidade tecnológica. No agregado, a economia brasileira apresentou em 1996, 47\% atingiu em 2013 43\%.

De fato, parte dessa queda também pode ser explicada pela perspectiva de Arend (2009) e Arend e Fonseca (2012) no sentido de que em função da não internalização dos métodos geradores do progresso técnico, o Brasil tornou-se paulatinamente dependente de decisões de investimento externas à economia nacional, implicando em certa medida na limitação da estratégia de desenvolvimento tecnológico. Essa condição encontra respaldo nas colocações de Suzigan (1991) ao afirmar que no momento de mudança do paradigma técnico não se empreenderam esforços na construção das bases de sustentação para o novo modelo técnico produtivo em curso.

Nestas condições, analisando-se a balança comercial brasileira percebe-se a lenta trajetória rumo à especialização regressiva, apontada por Laplane e Sarti (2006). O Brasil tem se estabelecido no plano internacional como exportador de commodities, e absorvedor de produtos de média alta e alta intensidade tecnológica, aliado ao agravante da doença holandesa conforme exposta por Bresser Pereira (2013) e Bresser Pereira e Gala (2006), cujo efeito sobre o câmbio tende a limitar os investimentos em atividades produtivas que se encontram no estado da arte industrial, e por consequência contribuem para a desindustrialização.

Enfim, a atualidade tem mostrado que se até 2005 podia-se constatar que "o passado havia cobrado do presente os 25 anos em que a estratégia de desenvolvimento delegou ao capital estrangeiro o papel de agente transformador e financiador do crescimento, como apontaram Arend e Fonseca (2012), os dados analisados sugerem que o passado não só continua cobrando as falhas de estratégia, como o presente tem paulatinamente restringido o tamanho das janelas de acesso ao novo paradigma técnico produtivo do futuro.

\section{Referências bibliográficas:}

AREND, M. A industrialização do Brasil ante a nova divisão internacional do trabalho. In: IPEA. Presente e Futuro: desafios ao desenvolvimentismo brasileiro. IPEA, 2014.

AREND, M. Anos de industrialização do Brasil (1955-2005): uma análise evolucionária. Porto Alegre: 2009. 50. Tese de Doutorado. Tese (Doutorado)-Faculdade de Ciências EconômicasUniversidade Federal do Rio Grande do Sul. 2009.

AREND, M.; FONSECA, P. C. D. Brasil (1955-2005): 25 anos de catching up, 25 anos de falling behind. Revista de Economia Política, v. 32, n. 1, p. 33-54, 2012.

BLACKABY, F. T. (1978). De-industrialisation. Heinemann Educational Books. London.

BONELLI, Regis; PESSOA, Samuel; MATOS, Silvia. Desindustrialização no Brasil: fatos e interpretação. $O$ futuro da indústria no Brasil: desindustrialização em debate. Rio de Janeiro: Civilização Brasileira, p. 201-225, 2013.

BRESSER-PEREIRA, L. C.; MARCONI, N. "Doença holandesa e desindustrialização." Valor Econômico 25, 2009.

BRESSER-PEREIRA, L. C.; MARCONI, N. Existe Doença Holandesa no Brasil? IV Fórum de Economia da Fundação Getúlio Vargas. 2008.

BRESSER-PEREIRA, Luiz Carlos. Maldição dos recursos naturais. Folha de S. Paulo, v. 6, n. 06, 2005.

CAIRNCROSS, Alec. (1978). What is De-industrialisation? In: Blackaby, F. (ed.), Deindustrialisation. Heinemann Educational Books. London. 
CANO, W. A desindustrialização no Brasil. Campinas: Instituto de Economia/Unicamp, (Texto para discussão n. 200), 2012.

CARNEIRO, R. Crise, ajustamento e estagnação, a economia brasileira do período de 197489. Economia e Sociedade, v. 2, n. 1, p. 145-169, 2016.

CARNEIRO, R. Impasses do desenvolvimento brasileiro: a questão produtiva. Textos para Discussão, Campinas: IE/UNICAMP, n. 153, nov. 2008.

CARNEIRO, R. Desenvolvimento em crise: a economia brasileira no último quarto do século XX. Unesp, 2002.

COMIN, A. A desindustrialização truncada:: perspectivas do desenvolvimento econômico brasileiro.. 2009. 271 f. Tese (Doutorado) - Curso de Economia, Economia, Universidade Estadual de Campinas, Campinas, 2009.

COUTINHO, L. A especialização regressiva: um balanço do desempenho industrial pósestabilização. Brasil: desafios de um país em transformação. Rio de Janeiro: José Olympio, p. 84-115, 1997.

FEIJÓ, C. OLIVEIRA, D. "Mudanças estruturais na economia brasileira e seus impactos sobre a evolução da produtividade na indústria de transformação pós- 1990” In: AZEVEDO, A.F; FEIJÓ, C; CORONEL, D.A. (orgs). A Desindustrialização Brasileira. Editora Unisinos, São Leopoldo. 2013.

FERRAZ, J. C.; KUPFER, D; HAGUENAUER, L.. Made in Brazil: desafios competitivos para a indústria. Rio de janeiro: Campus, p. 386, 1995.

JAEGERS, Thomas; LIPP-LINGUA, Carmen; AMIL, Digna. High-technology and medium-high technology industries main drivers of EU-27's industrial growth. Statistics in Focus, v. 1, 2013.

LAPLANE, M.; SARTI, F. Prometeu Acorrentado: o Brasil na indústria mundial no início do século XXI. Política Econômica em Foco, n. 7, p. 271-291, 2006.

LAZZARINI, S. G.; JANK, M. S.; INOUE, CFK. Commodities no Brasil: maldição ou bênção. O futuro da indústria no Brasil: desindustrialização em debate. Rio de Janeiro: Civilização Brasileira, p. 201-225, 2013.

MACARINI, J. P. A política econômica da ditadura militar no limiar do "milagre" brasileiro: 1967/69. Campinas: IE/UNICAMP, (Texto para discussão, n. 99) 2000.

MACARINI, J. P. A política econômica do governo Médici: 1970-1973. Nova economia, v. 15, n. 3, p. 53-92, 2005.

MORCEIRO, Paulo César. Desindustrialização na economia brasileira no período 2000- 2011: abordagens e indicadores. Coleção PROPG Digital (UNESP), p. 301 p.: il., gráfs., tabs., 2012.

OREIRO, José Luis; FEIJÓ, Carmem A. Desindustrialização: conceituação, causas, efeitos e o caso brasileiro. Revista de economia política, v. 30, n. 2, p. 219-232, 2010.

PALMA, José Gabriel (2005). Quatro fontes de “desindustrialização” e um novo conceito de "doença holandesa”. Trabalho apresentado na Conferência de Industrialização, Desindustrialização e Desenvolvimento, organizada pela FIESP e IEDI. Centro Cultural da FIESP, 28 de Agosto de 2005. 
PALMA, José Gabriel (2008). "De-industrialization”, “premature” de-industrialization and the Dutch Disease. In: Durlauf, S. N.; Blume, L. E. (org.), The New Palgrave Dictionary of Economics. Second Edition. Palgrave Macmillan.

ROWTHORN, R. e COUTTS, K. Commentary: Deindustrialisation and the balance of payments in advanced economies. Cambridge Journal of Economics. vol. 28, no. 5, 767-790. 2004.

ROWTHORN, R.; RAMASWAMY, R. Deindustrialization: causes and implications. International Monetary Fund, Staff Studies for the Economic Outlook, pp.61-77, December, 1997.

ROWTHORN, R.; RAMASWAMY, R. Growth, trade, and deindustrialization. IMF Staff papers, p. 1841, 1999.

SAMPAIO, D. P, Desindustrialização e estruturas produtivas regionais no brasil. 2009. $256 \mathrm{f}$. Tese (Doutorado) - Curso de Economia, Economia, Universidade Estadual de Campinas, Campinas, 2015.

SARTI, F.; HIRATUKA, C., Desenvolvimento industrial no Brasil: oportunidades e desafios futuros. Campinas: IE. Unicamp, 2011.

SILVA, H. C. O processo de desindustrialização: uma avaliação sob a perspectiva da economia brasileira (1990-2010). 157 f. Dissertação (Mestrado) - Curso de Economia, Economia, Universidade Federal de Santa Catarina, Florianópolis, 2012.

SINGH, A. (1977). UK Industry and the World Economy: A case of Deindustrialization? Cambridge Journal of Economics. Vol. 1, $\mathrm{n}^{\circ} 2$, june.

SOARES, C; TEIXEIRA, A; OREIRO, J.L. Uma Análise Empírica dos Determinantes da Desindustrialização no Caso Brasileiro In: AZEVEDO, A.F; FEIJÓ, C; CORONEL, D.A. (orgs). A Desindustrialização Brasileira. Editora Unisinos, São Leopoldo. 2013.

SUZIGAN, W. Situação atual da indústria brasileira e implicações para a política industrial. Planejamento e Políticas Públicas, Rio de Janeiro, n. 6, 1991.

TREGENNA, Fiona. Characterising deindustrialisation: An analysis of changes in manufacturing employment and output internationally. Cambridge Journal of Economics, v. 33, n. 3, p. 433-466, 2009.

UNCTAD. World Development Report. Genebra, 2003. 